\title{
Evaluation of twenty four new Gossypium hirsutum strains for growth, yield, fibre quality and ClCuV resistance under environment of Punjab, Pakistan
}

\author{
${ }^{*}$ M. Hassan, M. A. Haq, M. Aslam, M. Saleem, K. P. Akhtar and S. Sarwar Alam
}

Mutation Breeding Division, Nuclear Institute for Agriculture and Biology, Faisalabad, Pakistan

Received 15 October 2005; $\quad$ revised 16 November 2005; $\quad$ accepted 25 November $2005 \quad$ available online 22September 2005

\begin{abstract}
Twenty four new strains were tested for their yield, quality and Leaf Curl Virus (ClCuV) resistance. NIAB-111/S, NIAB-98 and NIAB-999 were significantly high fruit bearing varieties at 90 days completing 59.54, 48.26 and $46.00 \%$ fruiting respectively. Seed cotton yield of VH-142 was highest with $5417 \mathrm{kgha}^{-1}$ and 52 per plant boll bearing, DNH-57 and NIAB-999 remained second and third with 5234 and $5095 \mathrm{~kg} \mathrm{ha}^{-1}$ seed cotton yield, respectively. BH-160 and CRIS-467 were found to be second and third highest boll bearing varieties with 50.97 and 40.20 per plant average bolls respectively. Plant height in CRIS-467, MNH-642 and SLH-224 was significantly higher in comparison to other varieties.NIAB-98, CIM-499 and CIM-506 were found short stature varieties in comparison with other but out of these NIAB-98 and CIM-506 were in high yielding position and CIM-499 was found medium yielder variety. GOT\% of MNH-642 remained highest having value of 45.00\%. While GOT\%. of NIBGE-1, CRIS-168 and CRIS-467 was at lowest position with 35.73, 35.89 and 36.62\% respectively. NIAB-111, CIM-499 and BH-160 were at first position in terms of fibre fineness with micronaire values 3.98, 4.00 and 4.07 ig/inch having fibre length 28.53, 31.38 and $30.23 \mathrm{~mm}$ respectively. Out of 26 varieties, 16 varieties resulted maturity index in the range of $85.03 \%$ and $90.30 \%$ with highest maturity index in case of NIBGE-1 (i.e. 90.30\%) followed by NIAB-999 and MNH-642 with 89.55 and 85.5\% respectively.CRIS-168, CRIS-468 and CRIS-467 were found viral susceptible.
\end{abstract}

Key words: $\mathrm{ClCuV}$, growth, yield, quality, resistance, cotton, Gossypium hirsutum

*Corresponding Author, E-mail: mhj407jb@yahoo.com

\section{INTRODUCTION}

Cotton is a major cash crop in Pakistan contributing about 2 percent of GDP and $8.2 \%$ of value added in Agriculture), with total area under crop 2.9 million hectare and production of 10.0 million bales averaging $571 \mathrm{~kg}$ seed cotton per hectare. In 1999-2000 the cotton production was 11.24 million bales which declined to 10.73 million bales in 2000-01, it further dipped to 10.61 million bales in the fiscal year 2001-02 and 10.21 million bales in 2002-03, the downslide continued till 2003-04 reaching 10.00 million bales with $1.6 \%$ lower yield than the last year(Eco. survey of Pak. 2003-04). Leaf curl virus $(\mathrm{ClCuV})$, heavy insect/pest attack and lack of resistant varieties were the main causes of this decline. Though a number of new cotton varieties were introduced for general cultivation recently yet their performance need improvement. The present investigation was, therefore, undertaken employing 26 strains for their Agronomic evaluation of yield, wider adaptability, disease resistance and quality. Muhammad (2001), reported variability among various genotypes of cotton for environmental adoptability for yield, lint percentage and fiber quality. Moser et al. (2000) reported variation in lint percentage, boll weight and maturity in different Gossypium strains. Keim et $a l$. (2000) recorded increase in yield by early season new varieties and full season Gossypium hirsutum varieties. Abdul-Razzaque (2000) found more yield in hybrid varieties compared to non hybrid in terms of bolls per plant and heavier bolls than the conventional cultivars. Ji-Congliang et al. (2000) characterized the high yielder varieties as strong boll setting capability (over $40 \%$ boll setting rate), medium boll weight (4-4.5 g) and high lint percentage (over $40 \%$ ). Afiah-SAN and Ghoneim-EM (1999) conducted experiments on 10 Egyptian cotton cultivars and concluded that cultivar Giza 83 and Giza 75 gave highest yield due to higher number of bolls per plant and boll weight. Badr-SS (1999) studied Egyptian cotton (Gossypium) cultivars (Giza 87 and Giza 88) and four commercial cultivars and recorded a highly significant difference between 
cultivars, environment and cultivar $\mathrm{x}$ environment interaction. Giza 88 produced the highest overall yield, seed index and boll weight. Giza 88 produced superior fiber than all other cultivars. Vieira-R-de-M (1999) evaluated 10 commercial cotton (Gossypium hirsutum) cultivars for productivity and fiber characteristics. He found little difference among them with respect to yield though other parameters like boll weight, percentage fiber and technological characteristics of fiber varied significantly. Baloch-MJ et.al. (1997) evaluated ten Pakistani cotton varieties (Gossypium hirsutum) for seed cotton yield, lint percentage and fiber length and reported that varieties Sarmast and NIAB-78 were high yielder, CRIS-9 and NIAB-78 had high lint percentage and Qalandri, Shaheen, CIM-70 and CIM-109 had more fiber length. Kalsy and Grag (1989) observed that yield has direct correlation with boll number.Ba11s (1915) reported that staple length was a heritable chracter but it was subjected to environmental changes. Mirza and Chaudhry (1985) obtained all the hybrids statisti-By superior to both the standards i.e. MNH-93 and B-557. Ahmad and Panhwar (1987) expressed that, average yield per plant is the product of average boll weight and average number of bolls per plant in hybrid and standard variety Qalandri.They also recorded significantly longer staple length in hybrid compared to Qalandri.

\section{MATERIALS AND METHODS}

The present study was conducted in 2002-03 at Nuclear Institute for Agriculture and Biology, Faisalabad on sandy clay loam, alkaline (pH 8.0), nonsaline (EC: $0.30 \mathrm{~ms} / \mathrm{cm})$, low organic matter (0.92\%), Nitrogen (0.06\%), low available Phosphorus (8.0 ppm) and high exchangeable K (224.0 ppm) soil. Twenty four new strains of different research stations/institutes of Pakistan and one commercial variety CIM-473 (control), were tested for their performance related to yield, quality and disease resistance under the agro-climatic conditions of Faisalabad.The experimental design was randomized complete block with four replications. Plot size was $3.8 \times 4.8 \mathrm{~m}$, with planting density row to row $2.5 \mathrm{ft}$. and plant to plant $1.0 \mathrm{ft}$. All inputs such as water, fertilizer, weeds and pest control were managed in an optimal fashion. Three applications of nitrogen were made consisting of $50 \mathrm{~kg} \mathrm{Nha}^{-1}$ at sowing on 6th June, , $50 \mathrm{~kg} \mathrm{~N} /$ haat flowering stage in early August and $50 \mathrm{~kg} \mathrm{~N} / \mathrm{ha}$ at $50 \mathrm{~kg} \mathrm{Nha}^{-1}$ at boll development stage in the month of September. Phosphorus or $\mathrm{P}_{2} \mathrm{O}_{5}$ was uniformly applied to all the treatments AT $70 \mathrm{~kg} / \mathrm{ha}$ at sowing. The first irrigation was applied on 16th July and the remaining irrigations were applied fortnightly with final irrigation in the end October. Phenological data of the crop were recorded throughout the season on weekly basis. Germination percentage of every strain was checked, plant population was recorded by counting the total number of plants from every treatment, plant morphological characteristics and fruit bearing was monitored at regular intervals, CLCuV infestation at different growth stages was recorded by visual symptoms and then intensity was estimated by proportion of healthy and infested plants. Fifty boll samples were taken at random from each treatment and weighed. Seed cotton of five guarded plants was recorded and GOT percentage was calculated. Lint samples were analyzed for fiber qualitative studies. Fiber length, micronaire value and maturity index were measured by using fibro graph. To estimate total seed cotton production, all plots were harvested manually and weighed. Data were analyzed statistically by using computer M Stat-C program in accordance to procedures outlined by Steel and Torrie (1984).

\section{RESULTS}

\section{Germination Percentage and plant population}

Germination of CRIS-468, CRIS-467 and SLH-257 were found to be poor (ie.53, 63 and $73 \%$ respectively) which resulted in lower plant population.

\section{Fruit bearing and earliness}

NIAB-111, NIAB-98 and NIAB-999 were significantly higher fruit bearing strains within first 90 days completing 60, 48 and $46 \%$ of total fruit bearing indicating their earliness followed by CIM-506, CIM499, MNH-636, CIM-511, SLH-224 and DNH-57 with $43,42,42$, 41, 40 and 33\% mature bolls respectively as indicated in Fig. 1.

\section{Seed cotton yield in relation to mature bolls and plant population}

VH-142, DNH-57and NIAB-999 produced significantly higher seed cotton yield i.e. 5417, 5234 and $5095 \mathrm{~kg} / \mathrm{ha}$ with plant population 39675, 51510 and 51107 plants per ha while 52,40 and 40 boll bearing per plant and having average boll weight 4.05, 3.94 and $3.53 \mathrm{~g}$ respectively. Comparative growth, yield and quality performance of various candidate lines/ varieties of cotton presented at Table 1 . 
Evaluation of twenty four...

Plant height at maturity and comparative seed cotton yield

The plant height at harvest was maximum in CRIS467 (161 cm), MNH-642 (160.7 CM) and SLH-224 (159.4 cm). NIAB-98, CIM-499 and CIM-506 were short stature compared to others.

\section{Ginning out turn percentage (GOT \%)}

MNH-642 was found to be higher in GOT\% with $45.00 \%$ and MNH-635 with $44.59 \%$ respectively followed by MNH-636 and VH-142 with 43.33 and 42.42 GOT\% respectively.

\section{Micronaire value}

NIAB-111, CIM-499 and BH-160 were at first position in terms of fibre fineness with micronaire values 3.98, 4.00 and 4.07ìg/inch having fibre length 28.53, 31.38 and $30.23 \mathrm{~mm}$ respectively.

\section{Fibre length}

CIM-499, CIM-707, CIM-473, BH-160, FH-925,CIM497 and CIM-511 were ranked first by $31.38 \mathrm{~mm}$,
$30.85 \mathrm{~mm}, 30.72 \mathrm{~mm}, 29.77 \mathrm{~mm}, 29.42 \mathrm{~mm}$ and $29.38 \mathrm{~mm}$ respectively.

\section{Maturity index}

Highest maturity index in case of NIBGE-1 (i.e. $90.30 \%$ ) followed by NIAB-999 and MNH-642 with 89.55 and $85.5 \%$ respectively.

\section{CICuV response}

CRIS-168, CRIS-468 and CRIS-467 were found to be 9.77, 6.03 and $1.81 \%$ viral susceptible respectively.

\section{DISCUSSION AND CONCLUSION}

Germination percentage and plant population

Poor germination in CRIS-468, CRIS-467 and SLH257 (ie.53, 63 and $73 \%$ respectively) resulted in lower plant population of these varieties in the field conditions. Poor germination of these varieties may be due to genetic factor. While fair germination \%was recorded for CIM-499, BH-160, CIM-707, MNH-636 and SLH-257 (with 83, 84, 85, 86 and 88\% respectively) all the remaining varieties showed good germination (>90\%).

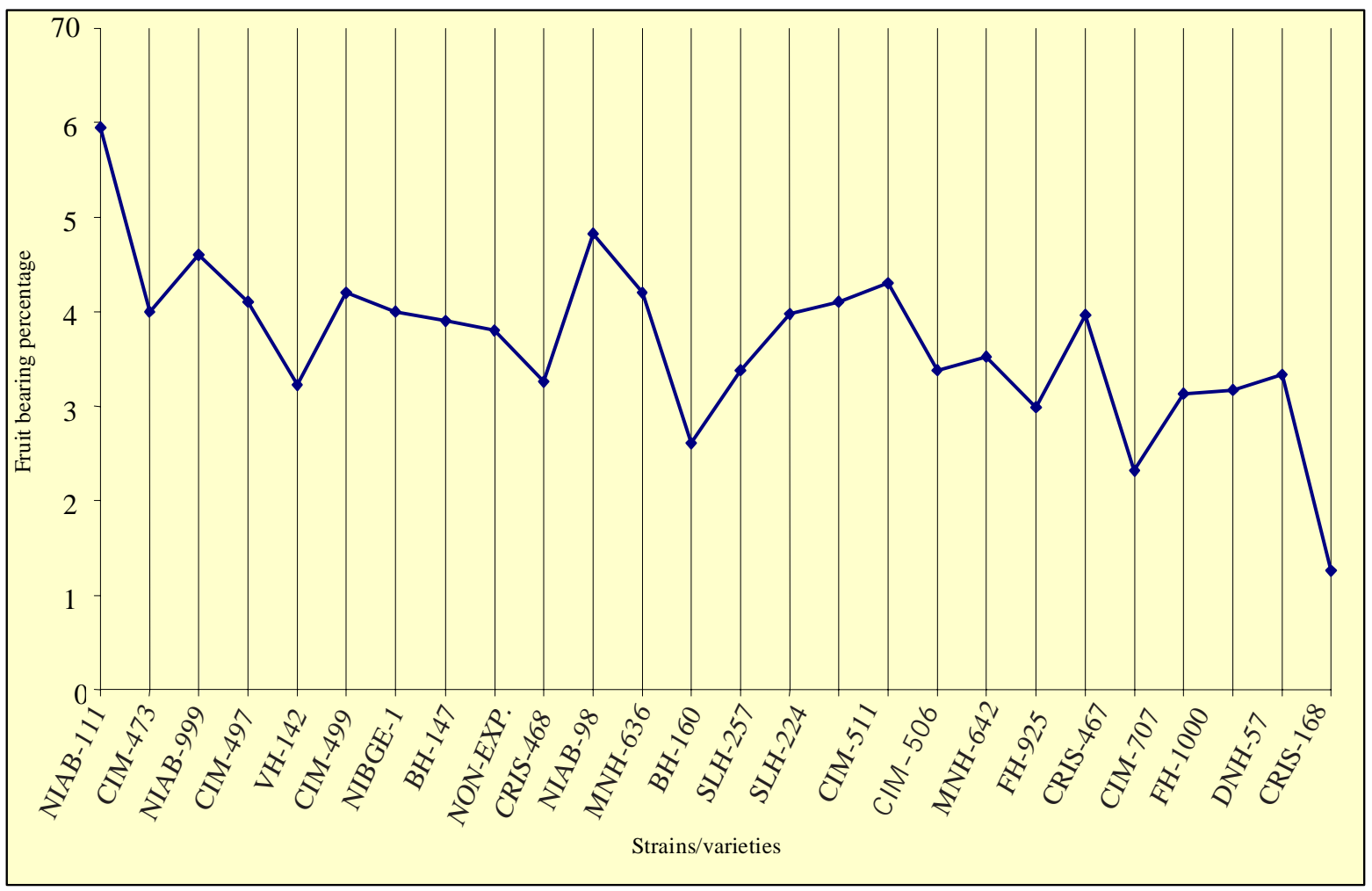

Fig.1: Fruit bearing by different strains at 90 days after sowing 


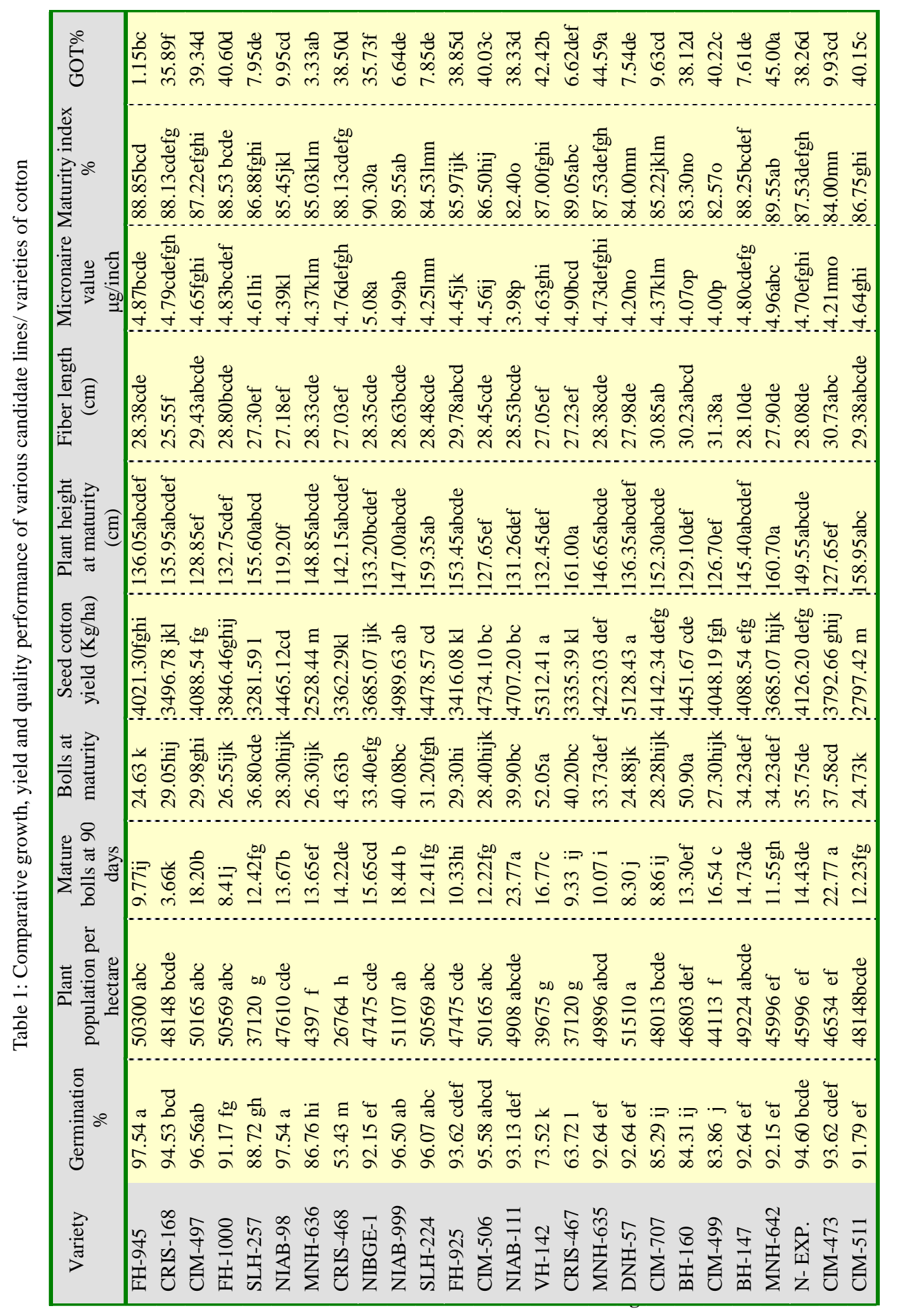


Evaluation of twenty four...

NIAB-111, NIAB-98 and NIAB-999 were significantly higher fruit bearing strains within first 90 days completing 60, 48 and $46 \%$ of total fruit bearing indicating their earliness followed by CIM-506, CIM499, MNH-636, CIM-511, SLH-224 and DNH-57 with 43,42, 42, 41, 40 and 33\% mature bolls respectively as indicated in Fig1. While CRIS-168, CRIS-467 and BH160 were the lowest fruit bearing with 13, 23 and $26 \%$. At maturity, VH-142 and BH-160 were significantly higher fruit bearing strains followed by CRIS-467 having 52.05, 50.90 and 40.20 average boll bearing per plant, respectively (Fig.1). Seed cotton yield of VH142 is also significantly higher. These findings are supported by Afiah-SAN and Ghoneim-EM (1999), Garg (1989) and Afzal (1949) but other two varieties did not fall in high yielder positions due to poor germination and lower plant population. This difference in fruit bearing among different varieties may be due to high degree of heterosis or due to variation in genotypic environmental interaction. Results are in agreement with those of Fryxell et al (1958) and Badr-SS (1999).

\section{Seed cotton yield in relation to mature bolls and plant population}

Out of twenty four strains sixteen produced significantly higher seed cotton yield over control CIM-473 and eight varieties produced significantly lower than the control. VH-142, DNH-57and NIAB-999 produced significantly higher seed cotton yield i.e. 5417,5234 and $5095 \mathrm{~kg} /$ ha with plant population 39675, 51510 and 51107 plants per ha while 52,40 and 40 boll bearing per plant and having average boll weight 4.05 , 3.94 and 3.53 g respectively. The increase in yield of seed cotton was associated with average number of bolls per plant and average boll weight. These results are in conformity with the findings of Moser et.al. (2000), Afiah-SAN (1999); and Kalsy and Grag (1989). CIM506 and NIAB-111 were ranked second high yielder strains with 4842 and $4819 \mathrm{~kg} / \mathrm{ha}$ seed cotton yield, per plant average bolls 39.90 and 37.58, plant population 50165 and 49089 plants per hectare and with average boll weight 3.96 and 4.08 grams, respectively. SLH-224 and NIAB-98 were ranked third high yielder varieties with 4476 and $4465 \mathrm{~kg} / \mathrm{ha}$ seed cotton yield, having 50569 and 47610 per hectare plant population, by 31.20 and 28.30 per plant average boll bearing, average boll weight 3.55 and $3.61 \mathrm{~g}$ and GOT\% 37.85 and 39.95, respectively but seed cotton yield of these varieties was statistically at par with NIAB-111/S and CIM-506.
The yield variation is due to heterosis in Agronomic characteristics of different strains. Results are in agreement with those of Marani (1963); Hawkins et al (1965), Young and Murray (1966) and Rafique (1972).

\section{Plant height at maturity and comparative seed cotton yield}

The plant height at harvest was maximum in CRIS467 (161 cm), MNH-642 (160.7 CM) and SLH-224(159.4 $\mathrm{cm})$. In terms of seed cotton yield and fruit bearing at different intervals during growth period, these varieties ranked much lower position. It indicates that in these strains maximum plant height does not contribute towards yield.

NIAB-98, CIM-499 and CIM-506 were short stature compared to others. Out of these NIAB-98 and CIM506 were in high yielding and CIM-499 was medium yielder variety.H-142, DNH-57 and NIAB-999 were medium stature varieties with plant height 132.4 , 136.4 and $147.0 \mathrm{~cm}$ respectively. Some varieties are faster growing during early growth stages, similar is the case of fruit bearing. These results are supported by Bozhinov, et al. (1998).

In some cases the plant height variation in field experimentation is due to soil variability but soil analysis from various locations of the field indicated that there is non significant variation in the field it may be due to poor plant population which provided an opportunity for vigorous growth with least competition for nutrition, moisture and aeration as is the case in CRIS-467, it is ranking at lower position in terms of plant population with 37120 plants per hectare but on the top position in case of plant height.

\section{Ginning out turn percentage (GOT \%)}

MNH-642 was found to be higher in GOT\% with $45.00 \%$ and MNH-635 with 44.59\% respectively followed by MNH-636 and VH-142 with 43.33 and 42.42 GOT\% respectively. Out of above mentioned four strains with higher GOT\% three strains i.e. MNH-642, MNH-635 and MNH-636 were at much lower position in terms of seed cotton yield while $\mathrm{VH}-142$ gave good performance in terms of seed cotton yield and GOT\%. NIBGE-1, CRIS-168 and CRIS-467 had lowest position with 35.73, 35.89 and $36.62 \%$ respectively. The variation in GOT\% among different strains can be due to environmental or genetic factor/ heterosis Fryxell et al. (1958) and Wu-Liqiang et.al (1999). 


\section{Micronaire value}

NIAB-111, CIM-499 and BH-160 were at first position in terms of fibre fineness with micronaire values 3.98 , 4.00 and 4.07 ìg/inch having fibre length 28.53, 31.38 and $30.23 \mathrm{~mm}$ respectively. Where as DNH-57, CIM473 and SLH-224 ranked second with micronaire values 4.19, 4.21 and 4.24 ìg/inch with fibre length 27.97, 30.72 and $28.48 \mathrm{~mm}$ respectively. MNH-636, CIM-707, NIAB98 and FH-925 ranked third with 4.36, 4.37, 4.39 and 4.44 ìg/inch micronaire value; and 28.33, 30.50, 27.17 and $29.77 \mathrm{~mm}$ fibre length; respectively. Six varieties had micronaire value ranging 4.50 to 4.70 , nine varieties gave 4.70 to $4.90 \mathrm{ig} / \mathrm{inch}$ and one variety the significant variation in micronaire values might be due to variable extent of climatic adoptability by different genotypes or it may be due to genetic factor.(* ref) A clear difference can be observed between NIAB varieties and others in term of earliness and fineness. NIAB varieties were early maturing with superior fibre. For example, NIAB111 was at the top in terms of fiber fineness and fruit bearing at 90 days.gave highest micronaire value i.e. 5.08 ìg/inch.

\section{Fibre length}

In case of fibre length seven varieties CIM-499, CIM707, CIM-473, BH-160, FH-925,CIM-497 and CIM-511 were ranked first by $31.38 \mathrm{~mm}, 30.85 \mathrm{~mm}, 30.72 \mathrm{~mm}$, $29.77 \mathrm{~mm}, 29.42 \mathrm{~mm}$ and $29.38 \mathrm{~mm}$ respectively. While remaining 18 varieties showed fibre showed fibre length ranging 27.02 to $29.00 \mathrm{~mm}$ and only one variety CRIS-168 had fibre length less than $27.00 \mathrm{~mm}$ (i.e. $25.55 \mathrm{~mm}$ ). The above mentioned varieties with high fiber length were unable to get high ranking position in case of seed cotton yield where as NIAB-98, NIAB111 and NIAB-999 proved to be medium fiber length (ranging $27.00 \mathrm{~mm}$ to $29.00 \mathrm{~mm}$ ) varieties and ranked among seven top yielder varieties hence these varieties can be more acceptable for farmers as well as industrialists. Variation in staple length is heritable character but it is subjected to environmental changes. These results are in confirmation with the fndings of Balls (1915).

\section{Maturity index}

Out of 26 varieties, 16 varieties resulted maturity index in the range of $85.03 \%$ and $90.30 \%$ with highest maturity index in case of NIBGE-1 (i.e. 90.30\%) followed by NIAB-999 and MNH-642 with 89.55 and 85.5\% respectively. These varieties were on top position in terms of higher micronaire value by showing 5.08, 4.99 and $4.95 \mathrm{ig} /$ inch respectively. But out of the above three varieties NIAB-999 was the only variety with top ranking position for seed cotton yield.

Remaining six varieties showed maturity ranging 84.53 and $82.40 \%$. With CIM-499 and NIAB-111 with lowest maturity index (82.40 and $82.57 \%$ respectively. This significant variation in maturity index can be most probably due to fluctuation in genotypic environmental interaction.

\section{CICuV response}

Cotton leaf curl virus (ClCuV) infestation under field conditions was also recorded on all the varieties. CRIS168, CRIS-468 and CRIS-467 were found to be 9.77, 6.03 and $1.81 \%$ viral susceptible respectively. In initial growth stage of the crop in the month of June July only 1-5\% viral infestation was recorded but in later August the damage was raised due to the abundance of white-flies in the field. Significantly lower seed cotton yield was produced from these varieties due to virus problem. A minute viral infestation (less than 0.5\%) was also recorded in DNH-57 and $\mathrm{BH}-160$ but this damage was much lower to cause any drastic impact on yield.

\section{REFERENCES}

Abdul-Razzaq, S., (2000). Assessment of Gossypium hirsutum F1 against commercial varieties, Pak.J.Sci. \& Ind. Res. 43(3), 184-187.

Afiah, S. and Ghoneim, E. M., (1999). Evaluation of some Egyptian cotton (Gossypium barbadense L.) varieties under desert conditions, Annals-of-Agric. Sci. Cairo. 44(1), 201-211.

Afzal, M., (1949). Growth and development of cotton plant and its improvement in the punjab. Govt. Printing Press, Lahore Balls W. L. 1915. Development and Properties of New Cot-tons. A \& C Block Ltd. London,107.

Baloch, E., (1997). Environmental adaptation analysis of several upland cotton varieties. Pak. J. Sci. \& Ind. Res. 41(5-12), 91-94.

Bozhinov M., (1998). Growth and development of Bulgarian and foreign cotton varieties.Rasteniev dni-nauki. 35(3), 384-388. 
Evaluation of twenty four...

Eco. Survey of Pak. (2003-04). Eco. Advisor's wing Isd:12-13 Fryxell P. A., Staten G., Porter J. H. 1958 Performance of some wide crosses in Gossypium. New Mex Agri Exp Sta Bull 419 1-15.

Hawkins, B. S., Peacock H. A. and Ballard W. W., (1965). Heterosis and combining ability in upland cotton; Effect on yield. Crop Science, 5, 543-546.

Ji, C., Yu, J., Liu, Y. L., Wu, Y., Ji, C. L., Yu, J., Liu, Y. L. and Wu, Y., (2000). Characteristics of yield constitution of high-yielding cotton varieties. Jiangsu. J. Agric. Sci. 16(1), 25-30.

Kalsy, H. S., Garg, H. R. (1989). Heterosis in intervarietal crosses of upland cotton (Gossypium hirsutum L). J. Ind. Sac. Cotton Impmv. 2, 159-162.

Marani, A., (1967). Heterosis and combining ability in intraspe-cific and inter-specific crosses of cotton. Crop. Sci. 7, 519-522.

Mirza, M. Y. and Chaudhry, M. R., (1985). Identification of parents for use in hybrid cotton programs in Pakistan. The Pak. Cottons. 29(2), 6375.

Mohammad, J. B., (2001). Stability and adaptability analysis of some quantitative traits in upland cotton varieties. Pak. J. Sci. \& Ind. Res. 44(2), 105-108.
Moser, H. S., Closkey M., Silvertooth J. C. and DuggerP., (2000). Performance of transgenic cotton varieties in Arizona. Proceedings of Beltwide cotton conferences, San Antonio, USA, 1, 497-499.

Keim, D. L., Burdett L., Jones K. R., Dugger P. and Richter D., (2000). Yield progress in delta pine conventional varieties grown in the Midsouth. Proceedings Beltwide cotton conferences, San Antonio, USA, 1, 545-547.

Rafique, M., (1972). Heterosis studies in G. hirsutum L crosses. M. Sc thesis, WPAU, Lyallpur. Steel, R. G. $D$. and J. H. Torrie, Principles and procedures of statistics Statistics. McGraw Co. Inc., Singapore, 172-177.

International study of cotton varieties in southern cone. Anais II Congresso Brasileiro de Algodao, 582-584.

Young, F. F., Murray, J. C., (1966). Heterosis and inbreeding depression in diploid and tetraploid cotton. Crop. Science. 6, 436-437. 